\title{
Isolated ST elevation in lead aVR during TMT at high workload as a marker of ostioproximal LAD occlusion
}

\author{
Iranna Hirapur, ${ }_{1}^{1}$ Rajeshwari Veeranna Mantgol, ${ }^{2}$ Navin Agrawal ${ }^{3}$
}

'Department of Cardiology, RL Jalappa Narayana Hrudayalaya Heart Center, Kolar, Karnataka, India

2Department of Opthalmology, RL Jalappa Narayana Hrudayalaya Heart Center, Kolar, Karnataka, India ${ }^{3}$ Department of Cardiology, Care Hospital, Surat, Gujarat, India

\section{Correspondence to}

Dr Navin Agrawal,

drnavinagrawal@gmail.com

Accepted 25 February 2014

\section{DESCRIPTION}

ST segment elevation in lead aVR of a resting ECG along with ST segment depression in multiple other leads during acute coronary syndrome (ACS) has been previously described to be a predictive marker of critical stenosis of the left main coronary artery or proximal left anterior descending artery (LAD). The importance of isolated ST segment elevation in lead aVR during a treadmill test (TMT) has never been stressed on before.

We present an interesting case of a 49-year-old man who presented with anginal chest pain, without a prior history of diabetes, hypertension or smoking. TMT performed 4 months ago was

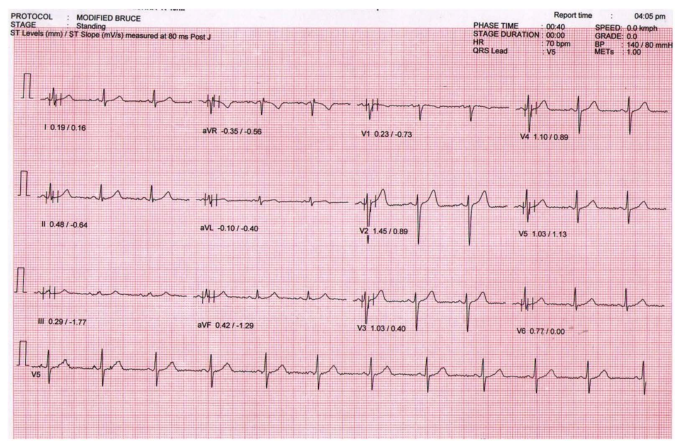

Figure 1 The standing ECG at baseline showing normal level of ST segment in lead aVR. reported negative by an experienced physician. There was ST elevation of $1.5 \mathrm{~mm}$ at peak exercise (10.21 Mets) and it persisted into recovery; there was no ST depression in any other leads (figures 1 and 2) with symptoms of fatigue and mild chest pain which were incorrectly presumed by the physician to be non-cardiac. The patient had a normal

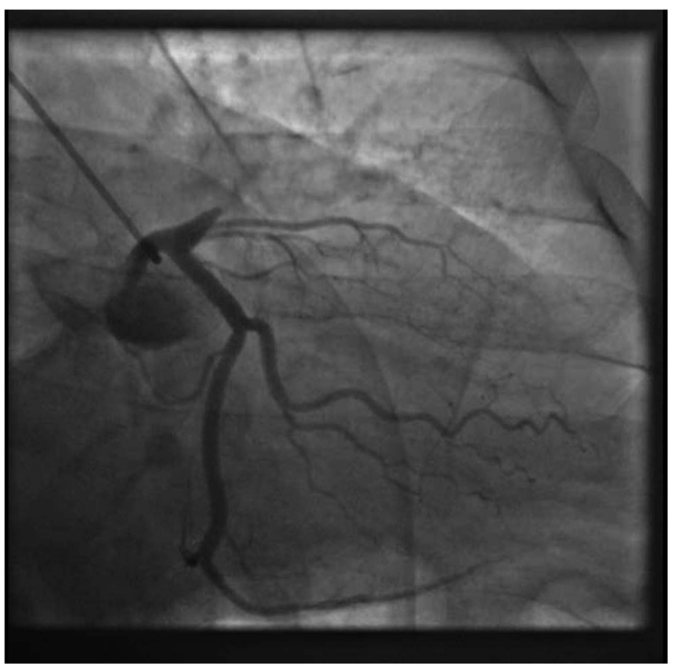

Figure 3 Fluoroscopic image in right anterior oblique caudal view showing proximally occluded left anterior descending coronary artery.

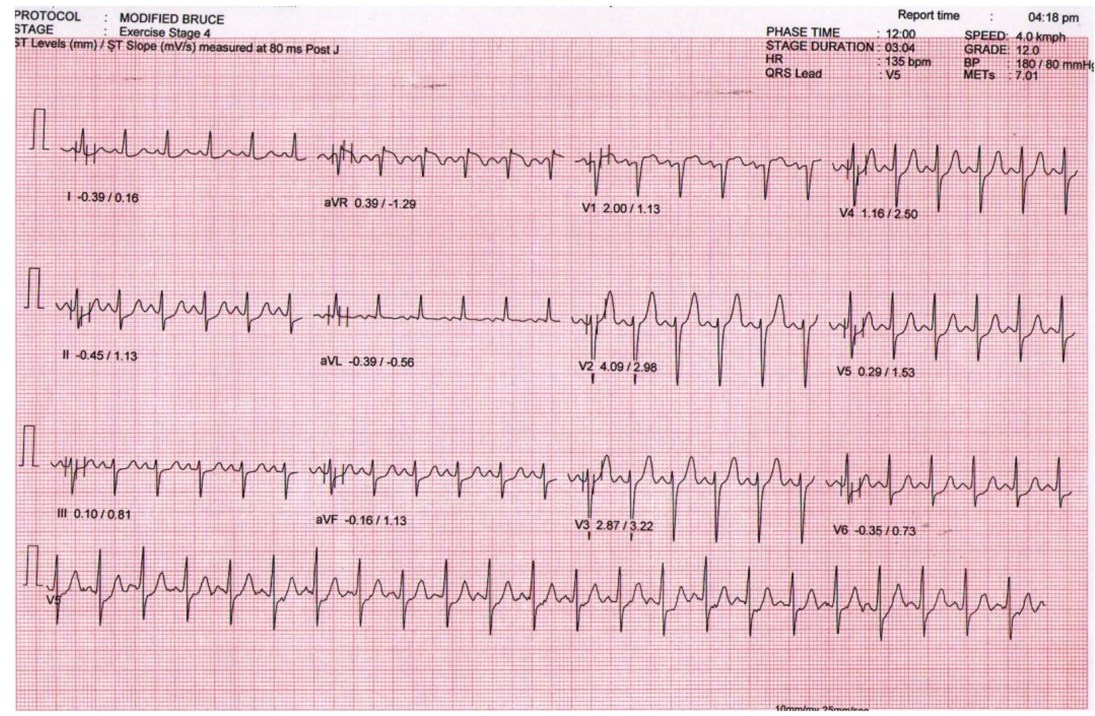

Figure 2 ECG recorded at the stage of peak exercise showing ST elevation in lead aVR without significant changes in other leads. 


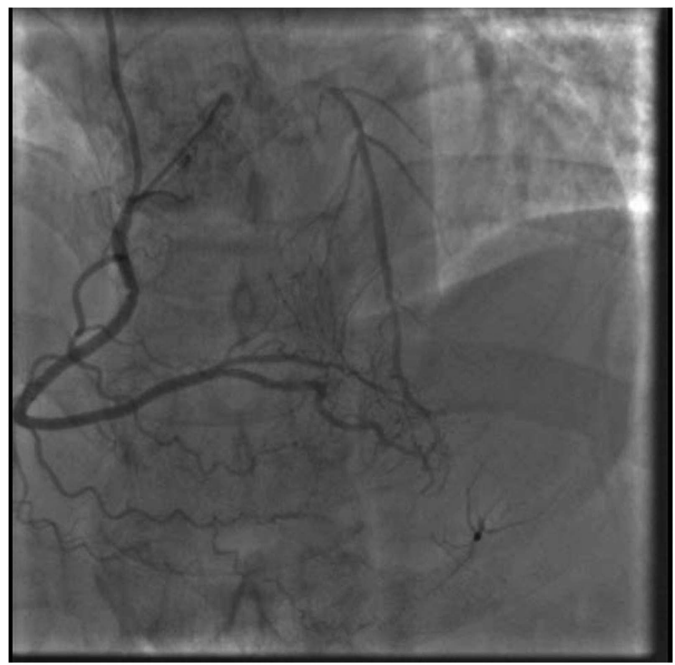

Figure 4 Fluoroscopic image showing retrograde filling of the left anterior descending coronary artery upto the proximal portion through collaterals from the right coronary artery.

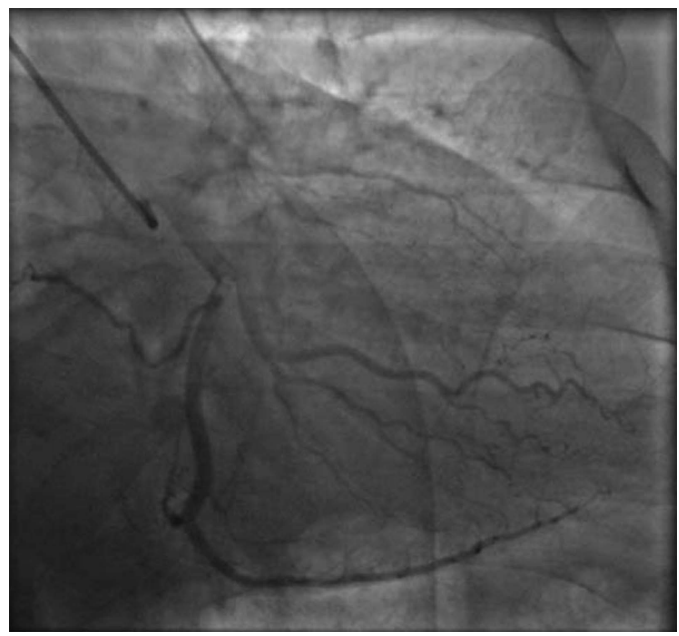

Video 1 fluoroscopic image in RAO caudal view showing proximally occluded Left anterior descending coronary artery.

echocardiogram which had no evidence of ischaemia or prior infarction at baseline.

Since symptoms were persistent a diagnostic coronary angiogram was performed. The angiogram revealed the presence of complete occlusion of the ostioproximal LAD, which filled retrogradely via RCA until the proximal segment (figures 3 and 4 , videos 1 and 2). The presence of good collateralisation, can explain the good effort tolerance. The patient was percutaneously revarcularised subsequently and a repeat TMT performed after 2 months of the procedure revealed that the ECG change had disappeared and so had the exertional symptoms. This retrospectively proved beyond doubt that the pain and the ECG change were ischaemia induced.

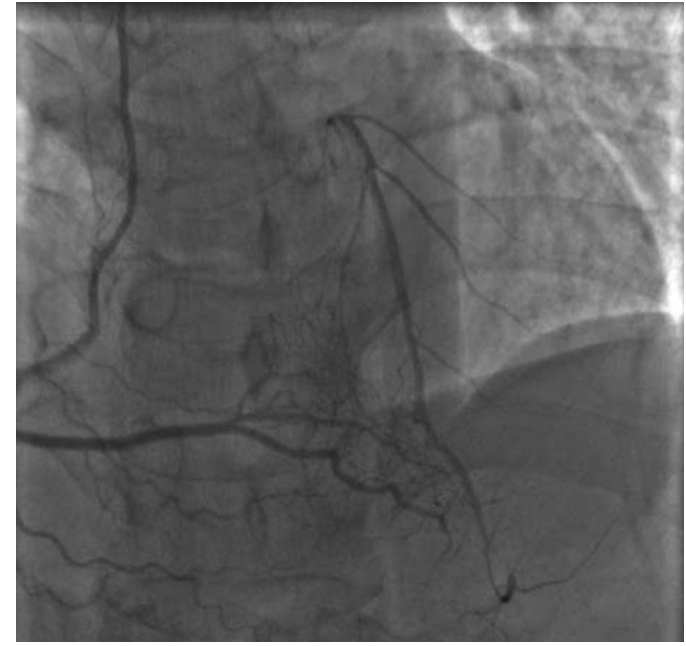

Video 2 Fluoroscopic image showing retrograde filling of the left anterior descending coronary artery upto the proximal portion through collaterals from the right coronary artery.

Another rare aspect of this disease was the fact that the patient had this ECG change at a high workload during the TMT which was missed, which stresses the importance of recognising this ECG change during TMT and also suggests an equivalent artery localising value of this ECG change as it is considered during ACS.

\section{Learning points}

- The role of isolated ST elevation in lead aVR as a marker of coronary artery disease during a treadmill test (TMT) has often been underestimated and can be easily missed as happened in our case.

- The importance of this ECG change during a TMT test as a marker of left anterior descending artery (LAD) occlusion is valid even when it occurs at a high workload

- Exercise induced ST elevation during TMT in lead aVR is an important indicator of significant left main coronary artery or ostial LAD stenosis and may have an equivalent localising value similar to what it has during an acute coronary syndrome.

Contributors All the authors have contributed in the drafting and the finalising of the manuscript.

Competing interests None.

Patient consent Obtained.

Provenance and peer review Not commissioned; externally peer reviewed.

\section{REFERENCE}

1 Uthamalingam $S$, Zheng $H$, Leavitt $M$, et al. Exercise-induced ST-segment elevation in ECG lead aVR is a useful indicator of significant left main or ostial LAD coronary artery stenosis. JACC Cardiovasc Imaging 2011;4:176-86. 
Copyright 2014 BMJ Publishing Group. All rights reserved. For permission to reuse any of this content visit http://group.bmj.com/group/rights-licensing/permissions.

BMJ Case Report Fellows may re-use this article for personal use and teaching without any further permission.

Become a Fellow of BMJ Case Reports today and you can:

- Submit as many cases as you like

- Enjoy fast sympathetic peer review and rapid publication of accepted articles

- Access all the published articles

- Re-use any of the published material for personal use and teaching without further permission

For information on Institutional Fellowships contact consortiasales@bmjgroup.com

Visit casereports.bmj.com for more articles like this and to become a Fellow 